Chinese Journal of Organic Chemistry

\title{
醌霉素类抗生素生物合成研究进展
}

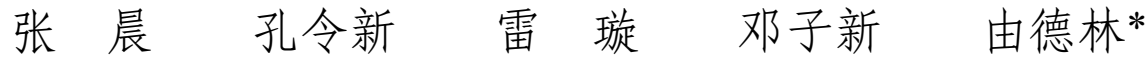 \\ (上海交通大学生命科学技术学院 微生物代谢国家重点实验室 上海 200030)
}

\begin{abstract}
摘要 醌霉素是一类由链霉菌产生的环状寡肽抗生素, 结构上拥有一对特征性喹喔啉-2-甲酰基或 3-羟基喹啉-2-甲酰 基单元. 醌霉素选择性插入到 DNA 分子的碱基对之间，抑制 DNA 的复制和转录，因而具有良好的肿瘤抑制活性. 综述 了近十年来醌霉素家族抗生素的生物合成研究进展，通过比较醌霉素不同代表成员的基因簇，归纳这些化合物与其它 类型天然产物生物合成以及色氨酸分解代谢中的相似反应，并剖析催化这些反应的酶的功能特性，揭示了醌霉素的化 学结构特征和其不同成员之间结构差异的形成原因. 在此基础上，还介绍了在异源宿主大肠杆菌中用组合生物合成的 方法产生醌霉素类非天然的天然产物的范例, 展示了该类抗生素工业化生产的潜力.
\end{abstract}

关键词 肿瘤抑制; 醌霉素; 天然产物; 生物合成

\section{Advance in the Research on Quinomycins Biosynthesis}

\author{
Zhang, Chen Kong, Lingxin Lei, Xuan Deng, Zixin You, Delin* \\ (State Key Laboratory of Microbial Metabolism and School of Life Sciences and Biotechnology, \\ Shanghai Jiao Tong University, Shanghai 200030)
}

\begin{abstract}
Quinomycins are a type of cyclic oligopeptide antibiotics, featuring a pair of moieties, either quinoxaline-2-carboxy or 3-hydroxyquinoline-2-carboxy group. The characteristic structural units are capable of intercalating preferentially into particular DNA basepairs, thereby inhibiting DNA replication and transcription and hence confer remarkable tumor-inhibiting potency to quinomycins. Herein, an overview is made about the development of the exploration on quinomycin biosynthesis mainly during the past decade. Biosynthetic gene clusters are compared among various quinomycin family members, common biochemical reactions experienced in the biosynthesis of these compounds and natural products of other types as well as tryptophan catabolism are inducted with functional characteristics of the enzymes responsible for these reactions dissected, concurrently lending profundity to the revelation of the reasons for the formation of structural features shared and variances differentiated by quinomycins. Based on the elaboration, an exemplar is presented about the combinatorial biosynthesis in E. coli, the heterologous host to produce the unnatural natural product of quinomycin family, showing the potentiality of industrialization for the biosynthesis.

Keywords tumor inhibiting; quinomycin; natural product; biosynthesis
\end{abstract}

天然产物是指由生物体在代谢过程中，经过一系列 生化反应产生的具有良好药理活性或生物活性的化合 物, 它们天然地存在于自然界中. 其中有一类天然产物 不是由核糖体合成的寡肽或多肽, 通常由细菌或真菌在 非维持自身生命所必需的次级代谢中合成. 这类肽命名 为非核糖体肽(NRP), 相应的负责合成这类肽的多酶体 系称为非核糖体肽合成酶(NRPS).

醌霉素(quinomycin)具有 NRP, 因此属于非核糖体 肽类的天然产物. 醌霉素家族的成员和其它所有非核糖
体肽类天然产物一样都依靠以模块为单元的 NRPS 合 成, 一般而言, 起始模块由识别和加载特定氨基酸的腺 苷酰化结构域(A-结构域)以及肽基载体蛋白结构域 (PCP)构成，而延伸模块除了这两种结构域外还含有缩 合结构域(C-结构域), 负责将本模块识别的氨基酸与前 一个模块的 $\mathrm{PCP}$ 上装载的氨基酸缩合形成新的肽键. 通 过这种方式, NRP 的肽链得以延伸直至最后一个氨基酸 被缩合 ${ }^{[1]}$. 通常 NRP 由硫酯酶催化从 NRPS 上释放, 但 也可能通过其它的机制释放 ${ }^{[2]}$. 此外, 醌霉素除了 NRP

\footnotetext{
*E-mail: dlyou@sjtu.edu.cn

Received January 9, 2014; revised February 17, 2014; published online March 10, 2014.

Project supported by the National Natural Science Foundation of China (Nos. 31170085, 31070058) and the Key Project of China National Programs for Fundamental Research and Development (No. 2012CB721004).

国家自然科学基金(Nos. 31170085, 31070058)、国家重点基础研究发展计划(No. 2012CB721004)资助项目.
} 
外, 还具有显著结构特征的喹喔啉或喹啉环生色团, 这 两种环的生物合成都起始于 $L$-色氨酸, 并且在初始阶段 经历着与色氨酸分解代谢非常相似的生化反应. 目前, 醌霉素多个成员的生物合成基因簇都已确定, 尽管在生 物合成机制上还有许多细节需要探究, 现有的关于它们 的生物合成途径研究十分系统, 并且基于这些研究, 综 合不同醌霉素结构特征的新型天然产物已经可以通过 大肠杆菌发酵产生. 本文将从醌霉素生物合成基因簇的 确定、醌霉素的生物合成途径研究以及以醌霉素的结构 改造为目的的生物合成三个方面进行综述.

\section{1 醌霉素家族的代表成员及其结构特征}

醌霉素是一类天然产物的总称, 这类天然产物除了 具有由两条相同的肽链首尾相连形成的大环内二酯
NRP 骨架，同时还具有一对喹喔啉-2-甲酰基(QXC)或 3差基喹啉-2-甲酰基(HQA)生色团. 常见的醌霉素有棘霉 素(echinomycin)、三骨素 A (triostin A)、SW-163C、 thiocoraline, 它们的 NRP 骨架均为 2 个相同的四肽链环 二聚化形成的八肽(图 1). 在棘霉素和三骨素 $\mathrm{A}$ 中, 它们 的 NRP 四肽单元的氨基酸序列从 $\mathrm{N}$ 端到 $\mathrm{C}$ 端的分别为 $D$ - 丝氨酸、 $L$-丙氨酸、 $L$ - 半胱氨酸和 $L$-㽰氨酸, 并且后 2 个氨基酸残基都在各自的 $\alpha$-氮上被甲基化. 在 SW-163C 中, 除了 3 个天然氨基酸残基以外, 还有 1 个 稀有氨基酸去甲冠烷酸 norcoronamic acid (NCA)残基也 参与形成 NRP 骨架 ${ }^{[3]}$. Thiocoraline 的 NRP 骨架的组成 与上述抗生素有很大差异, 其四肽链由 3 个甲基化的半 胱氨酸和 1 个甘氨酸组成, 并且在它的 NRP 内部并非都 是氨基酸残基的 $\alpha$-氨基和另一个氨基酸残基的 $\alpha$-羧基

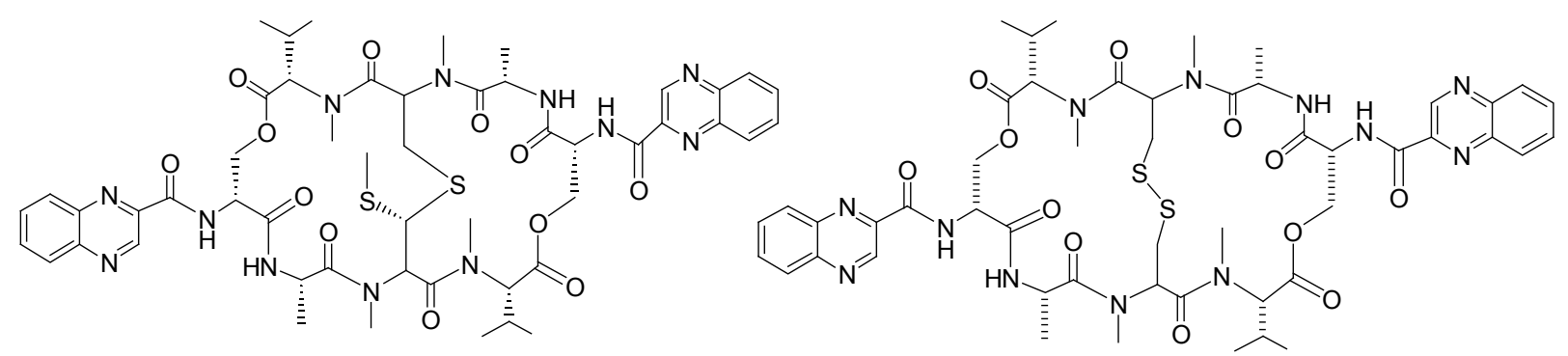

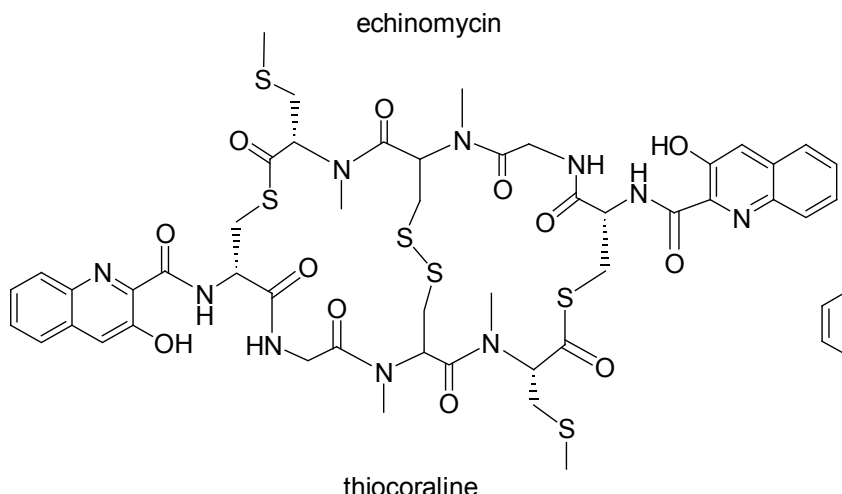

triostin A

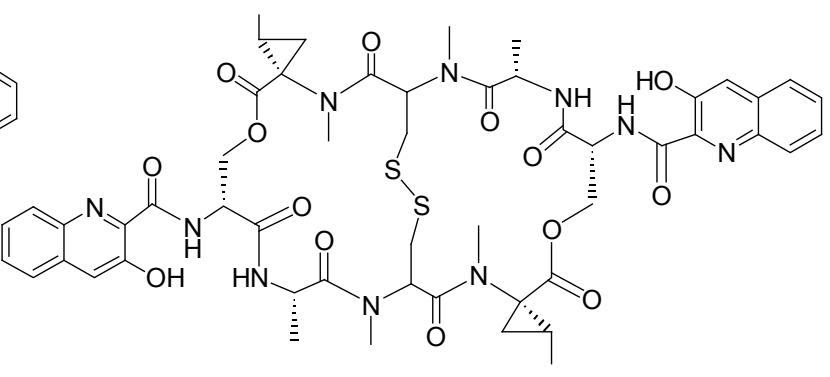

SW-163C

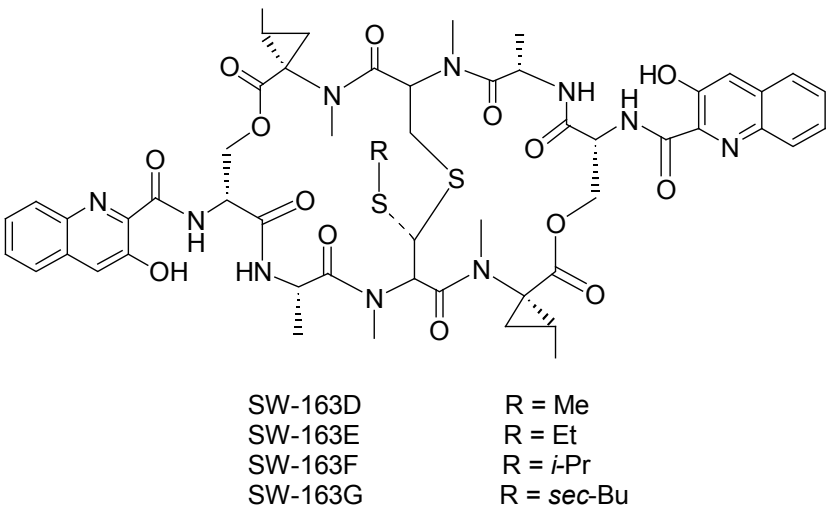<smiles>CC(=O)O</smiles><smiles>O=C(O)c1nc2ccccc2cc1O</smiles><smiles>CCC1(N)CC1</smiles>

图 1 醌霉素家族成员及其芳香族生色团和 SW-163 的非核糖体肽骨架中的去甲冠烷酸的化学结构

Figure 1 Chemical structures of members from quinomycin family, their aromatic chromophores and norcoronamic acid (NCA) in the NRP backbone of SW-163 
连接形成肽键. 醌霉素的 NRP 骨架中的两条相同肽链 除了首尾各以一个酯键连接以外, 在第 3 个氨基酸残基 即半胱氨酸残基之间还形成了特殊的连接方式. 在三骨 素 A、thiocoraline 和 SW-163C 中, 两个半胱氨酸以各自 的䘪基形成二硫键, 而在棘霉素中二硫键为硫缩醛结构 所代替(图 1). 醌霉素这类抗生素可以凭借它们的扁平 状生色团插入到 DNA 碱基对中, 并且插入序列具有一 定的偏好性, 这种偏好性是由它们的 NRP 骨架中的氨 基酸残基与 DNA 碱基中的原子依靠非共价键特异性相 互作用产生的. 由于生色团的插入, DNA 的复制和转录 都受到抑制 ${ }^{[4]}$, 因此, 很多细菌或真菌都受到醌霉素的 抑制, 甚至醌霉素也可以抑制肿瘤细胞的生长 ${ }^{[5]}$, 这种 抑制机理和我们所熟知的致癌剂溴化乙啶很类似. 醌霉 素在抑制肿瘤细胞生长的同时, 也能对正常细胞产生抑 制. 因此, 醌霉素生物合成的应用研究主要集中在如何 增加它对肿瘤细胞作用的专一性和减少对正常细胞的 毒性上。

\section{2 醌霉素生物合成基因簇的克隆与分析}

20 世纪 80 年代, Glund 等 ${ }^{[6]}$ 通过在棘露素产生菌中 喂养放射性同位素标记的 QXC 证明了 $\mathrm{QXC}$ 是棘霉素生 物合成的前体, 并推断 $L$-色氨酸是 QXC 合成的前体. 在三骨素 A 产生菌 S. triostinicus 中将利用 QXC 的酶分 离纯化出来, 对其进行活性研究, 发现在加入 QXC 和 ATP 时, 该酶能催化释放焦磷酸. 硅胶薄层层析检测发 现此酶促反应的产物之一与化学合成的腺苷酰化的 QXC 具有相同的迁移率, 于是推断该酶能将 QXC 进行 腺苷酰化. Schmoock 等利用三骨素生物合成的 NRPS 与 形成 NRP 骨架的氨基酸的特异性相互作用, 在三骨素 产生菌的菌丝体破碎物中分离纯化到了它们生物合成 的 NRPS. 利用之前分离到的 QXC 腺苷酰化酶的 $\mathrm{N}$ 端 序列设计 PCR 引物, 并利用一组 A-结构域 ACMSI、

$\mathrm{SnbA}$ 和 EntE 的保守序列设计出引物, 以三骨素产生菌 的染色体 DNA 作为模板, 进行 PCR 扩增, 得到一个 580 $\mathrm{bp}$ 的产物. 对该产物进行测序, 发现它的序列与原先已 知的 QXC 腺苷酰化酶 $\mathrm{N}$ 端序列一致并与 ACMSI、SnbA 和 EntE 显示出高度的序列相似性. 再用 ${ }^{32} \mathrm{P}$ 对该 PCR 产物进行标记, 并作为探针, 对三骨素产生菌的染色体 DNA 做 southern 杂交. 对具有阳性信号的片段测序发现 含有三骨素生物合成基因簇中的三个基因 $\operatorname{trs} A 、 \operatorname{tr} s B$ 和 trs C. Glund 等 ${ }^{[7]}$ 还利用 $\mathrm{QXC}$ 与 $\mathrm{QXC}$ 载体蛋白的特异性 相互作用分离纯化了该载体蛋白, 根据其 $\mathrm{N}$ 端序列设计 探针用于 southern 杂交克隆该载体蛋白基因. 测序结果 表明该载体蛋白的基因序列与产生三骨素的链霉菌主 代谢的脂肪酸合酶的酰基载体蛋白(ACP)序列完全一 致. 说明主代谢的脂肪酸合酶 ACP 就是三骨素生物合
成所需的 QXC 载体蛋白, 表明三骨素 A 的生物合成既 利用了主代谢途径也利用了次级代谢途径.

Watanabe 等 ${ }^{[8]}$ 于 2006 年利用 Schmoock 等所确定的 部分基因设计探针, 在 S. lasaliensis 的基因文库中篮选 到了棘霉素的生物合成基因簇(约 $36 \mathrm{~kb}$ ), 并确定基因簇 位于 S. lasaliensis 的线型质粒上. 将这个基因簇中的结 构基因及抗性基因分三组克隆到 3 个不同的可相容质粒 上, 并转化到大肠杆菌 E. coli BL21(DE3)中, 最终发酵 得到了棘霉素，从而确定了合成棘霉素必需的全部基 因，并在此基础上界定了棘霹素生物合成基因簇的范 围，同时也通过体内和体外实验证明了三骨素 $\mathrm{A}$ 作为棘 霉素生物合成途径的中间物被基因簇中的甲基转移酶 Ecm 18 催化将二硫键转化为硫缩醛结构, 从而直接生成 棘霉素. 由于以前的研究一直没发现三骨素 A 产生菌 $S$. triostinicus 能够产棘霉素, 于是他们推测 S. triostinicus 的三骨素 A 生物合成基因簇可能比 S. lasaliensis 中的棘 霉素生物合成基因簇缺少甲基转移酶 $\mathrm{Ecm} 18$ 的同源基 因, 然而他们将 S. triostinicus 中三骨素 A 的全部基因 簇(约 $36 \mathrm{~kb}$ ) 克隆并测序后发现这个基因簇中并不缺少 这个同源基因, 并且包含所有棘霉素基因簇中的结构基 因, S. triostinicus 基因簇中的甲基转移酶为 TrsK, 并且 在核苷酸水平上与 $\mathrm{Ecm} 18$ 的相似度达到 $82 \%$. 通过改进 发酵条件, 使 S. triostinicus 产生了极少量的棘霉素. 尽 管如此, 导致 S. lasaliensis 与 S. triostinicus 在棘霉素产 量上的巨大差异的原因尚不清楚 ${ }^{[9]}$.

上海交通大学由德林课题组 ${ }^{[10]}$ 在 Schmoock 和 Watanabe 等研究结果的基础上, 在灰色变异链霉菌万 隆亚种 S. griseovariabilis subsp. bandungensis subsp. nov 中确定了棘霉素的生物合成基因簇. 它与 S. triostinicus 中的相同，与 S. lasaliensis 中的基因簇明显不同，并且 与前者的同源性平均高达 $90 \%$ 以上，而与后者平均只有 $70 \%$ 以上.

与此同时, Lomb 等 ${ }^{[11]}$ 对 thiocoraline 的产生菌 Micromonospora sp. ML1 进行了研究, 他们根据 thiocoraline 的 NRP 骨架的组成, 利用半胱氨酸和甘氨 酸的腺苷酰化结构域保守序列设计出探针, 以 Micromonospora sp. ML1 的染色体 DNA 为模板, 扩增 出 6 条 PCR 产物, 用这 6 条产物对基因组文库进行菌落 原位杂交, 篮出了若干阳性菌落, 并结合分子遗传学和 LC-MS 检测，最终确定了 thiocoraline 生物合成基因簇 (约 $53 \mathrm{~kb}$ ). 将这个基因簇在 S. albus 和 S. lividans 中异源 表达, 最终它们都能产生 thiocoraline. 基因簇测序发现 其中有 2 个 NRPS 蛋白 TioR 和 TioS, 生物信息学预测 认为它们的 A-结构域识别的氨基酸正好是 thiocoraline 的 NRP 骨架形成所需的氨基酸, 因而推断它们负责 
thiocoraline 的 NRP 骨架的生物合成, 然而另外还发现 2 个 NRPS 蛋白 TioY 和 TioZ, 由于它们的 A-结构域识别 的氨基酸与 NRP 骨架无关, 故推断它们不参与 NRP 骨 架的生成, 但推测它们合成的肽链可能会对 thiocoraline 的生物合成起调控作用.

\section{3 醌霉素芳香族生色团的生物合成}

\subsection{QXC 与 HQA 的合成代谢及其与主代谢的内在联} 系

醌霉素抗生素有两种芳香族前体 QXC 或 HQA. 2006 年, Watanabe 等 ${ }^{[12]}$ 用化学方法合成同位素标记的 $(2 S, 3 S) \beta$-差基色氨酸和 $(2 S, 3 R) \beta$-羊基色氨酸进行喂养 实验将 $(2 S, 3 S) \beta$-差基色氨酸确定为 $\mathrm{QXC}$ 生物合成的中 间体，结合在 $S$. lasaliensis 中克隆的棘霉素生物合成基 因簇的序列信息提出了 QXC 的生物合成模型. 2010 年, 他又用化学方法体外合成 $(2 S, 3 R) \beta$-羟基犬尿氨酸进行 喂养实验, 将其确定为 $\mathrm{QXC}$ 生物合成的中间体, 从而
进一步证明了先前提出的生物合成假说. 同时, Sheoran 等 ${ }^{[13]}$ 于 2008 年、参照 Watanabe 等的假说并结合 thiocoraline 的生物合成基因簇序列信息，提出了 thiocoraline 的芳香族前体 HQA 的生物合成途径假说.

以 S. lasaliensis 中的棘霉素基因簇为例, $\mathrm{QXC}$ 的生 物合成途径中 $L$-色氨酸(1)需要先加载到 NRPS 蛋白 $\mathrm{Ecm} 13$ 的 PCP 结构域上, 然后被细胞色素 P450 羟化酶 $\mathrm{Ecm} 12$ 催化, 在色氨酸的 $\beta$ 位碳原子上加上羟基. 接下 来, 硫酯酶 $\mathrm{Ecm} 2$ 催化水解反应，将 $(2 S, 3 S) \quad \beta$-差基色氨 酸(4)从 Ecm 13 上释放下来. 经过色氨酸 2,3-双加氧酶 $\mathrm{Ecm} 11$ 催化, 吲哚环打开, 产生 $N$-甲酰- $\beta$-羟基犬尿氨酸 (5), 经过水解酶 Ecm14 催化产生 $(2 S, 3 R) \beta$-羊基犬尿氨 酸(7). 再经过依赖于 FAD 的氧化还原酶 Ecm4 催化发生 氧化重排, 产生 $N$-(2'-氨基苯基)- $\beta$-羟基天冬氨酸(12), 接下来发生 $\mathrm{Ecm} 3$ 催化的脱氢反应，再经历 3 步非酶促 的脱羧、成环和脱氢反应，最终形成 $\mathrm{QXC}(\mathbf{1 6})\left(\right.$ 图 2) ${ }^{[9]}$. 该途径中，从 5 至 16 之间的反应尚缺乏体外实验证明.

EC1.13.11.11

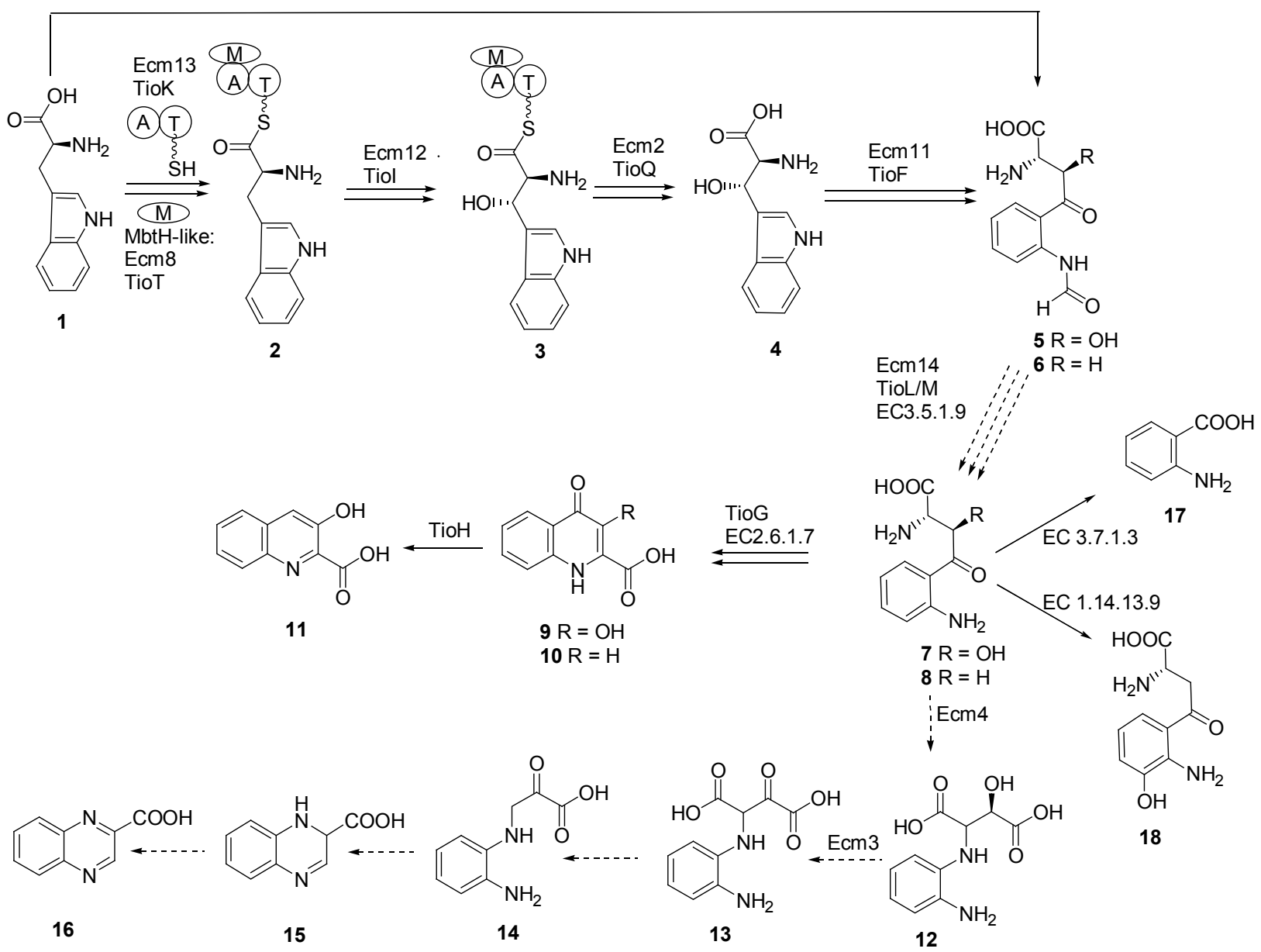

图 2 棘霉素与 thiocoraline 的芳香族前体喹喔啉-2-甲酸与 3-羊基喹啉-2-甲酸的生物合成假说以及色氨酸的分解代谢途径 Figure 2 Proposed hypothesis on biosynthetic pathway of the aromatic precursor of echinomycin and thiocoraline, quinoxaline-2-carboxylic acid and 3-hydroxyquinaldic-2-carboxylic acid and tryptophan catabolic pathway 
以 Micromonospora sp. ML1 的 thiocoraline 基因簇 为例, HQA 的生物合成途径中最初的几步反应与 $\mathrm{QXC}$ 生物合成途径相同, 直到生成 7, 在接下来的反应中, 7 被转氨酶 TioG 催化, 将一个氨基变成羰基并成环, 产 生 9, 再经过一个脱氢酶 TioH 催化形成 HQA(11)(图 2) ${ }^{[14]}$.

不仅 QXC 与 HQA 的生物合成存在许多相似点, 而 且它们与色氨酸分解主代谢也有诸多相似之处. 两种次 级代谢在 $\mathbf{4}$ 生成以后与主代谢一样都经历了色氨酸双加 氧酶催化的吲哚环氧化开环和酷酶催化的 $N$-甲酰基的 水解产生 7 , 但主代谢中色氨酸双加氧酶是以 $L$-色氨酸 为底物, 这个差别就造成了在这两步反应中主代谢和次 级代谢产物的在 $\beta$ 碳原子上少一个羟基, 主代谢中这两 步反应完成后产生的是 $L$-犬尿氨酸 $(\mathbf{8})$, 这是由次级代 谢中这两步反应之前 $L$-色氨酸经历了在主代谢中没有 的 $\beta$-羟化造成的, 而与这两步反应本身无关. 主代谢在 8 生成后形成三个分支途径, 第一个分支途径是 8 由转 氨酶 EC2.6.1.7 催化并成环产生犬尿喹啉酸 (10, kynurenate), 这一反应与 HQA 生物合成途径中 7 经历的 转氨酶 TioG 催化的反应相似, 它们的产物也只有前述 的 $\beta$ 位羟基的差异, 因此单就此分支途径而言, 主代谢 与 HQA 的生物合成十分相似, 主代谢的第二条分支途 径中 8 将裂解为丙氨酸和邻氨基苯甲酸 $(17$, anthranilate), 第三条分支途径中 8 会被犬尿氨酸 3-单加氧酶 $\mathrm{EC} 1.14 .13 .9$ 催化产生苯环上被羟基化的 3-羟基犬尿氨 酸(18), 尽管该酶与 QXC 生物合成途径中依赖于 FAD 的氧化还原酶 $\mathrm{Ecm} 4$ 在氨基酸水平上同源性达到 34\%, 但是按照生物合成途径假说, Ecm4 催化 7 发生十分复杂 的氧化重排反应, 远非主代谢中简单地将苯环羟化, 因 此其产物与 $\mathbf{1 8}$ 有很大结构差异. 与 QXC 和 HQA 的生 物合成途径不同一样, 也正是从这一步反应开始, QXC 的生物合成与主代谢途径发生了分支(图 2). 此外, 体外 研究表明 thiocoraline 生物合成中的氨基转移酶 TioG 除 了能催化 7 产生具有羟基的 9 以外，也能催化主代谢中 间物 8 发生相同反应, 产生缺少羟基的 10 (图 2), 这暗示 着 TioG 在一定程度上能够代替 EC2.6.1.7 的功能 ${ }^{[14]}$. 此 外，从 QXC 生物合成途径中 $\mathbf{1}$ 至 $\mathbf{5}$ 这几步已被证实的 反应来看, 上述三条代谢途径表现出的相似性也暗示了 催化这几步反应的酶可能在功能上互补. 由于 QXC 生 物合成途径中 7 经历的氧化重排反应尚未得到验证, 因 此确定 QXC 的生物合成途径以及进一步阐明三种途径 的内在联系, 对该氧化重排反应的研究也是十分必要 的.

\section{2 类 $\mathrm{MbtH}$ 蛋白}

在棘霉素、三骨素 A、SW-163C 和 thiocoraline 的
生物合成基因簇中都发现了一个编码大约 70 个氨基酸 的分子量较小的蛋白基因, 分别为 ecm8、trsH、swb18 和 tioT. 它们都与最早在分支杆菌生长素生物合成基因 簇中发现的 $m b t H$ 基因高度同源, 因此它们连同所有其 它与 $m b t H$ 高度同源的基因都被统称为类 $m b t H$ 基因. 事 实上, 类 $m b t H$ 基因广泛存在于 $\mathrm{NRP}$ 抗生素的生物合成 基因簇中. 类 $\mathrm{MbtH}$ 蛋白由约 70 个氨基酸组成, 序列高 度保守，实验证明不同基因簇甚至不同菌株中的类 $m b t H$ 基因可以互补 ${ }^{[15]}$. 类 $\mathrm{MbtH}$ 蛋白除了单独存在以 外，也可以一个结构域的形式存在于 NRPS 蛋白中. 对 包括棘霉素在内的一组 NRP 类抗生素 novobiocin、 clorobiocin、 simocyclinone D8 和 vancomycin 的生物合 成研究发现: 除 novobiocin 外, 在其余几种抗生素的生 物合成中, 类 MbtH 蛋白对 NRPS 的氨基酸加载活性起 着必不可少的辅助作用 ${ }^{[16 ~ 20]}$. 并且 Lutz Heide 通过对链 霸溶菌素生物合成中含有类 MbtH 结构域的 NRPS 蛋白 $\mathrm{SlgN} 1$ 的空间结构研究, 证实了这种辅助作用是依靠类 MbtH 蛋白与 NRPS 蛋白的 A-结构域互作而实现的 ${ }^{[21]}$.

\subsection{A-PCP 双结构域 NRPS 蛋白}

在醌霉素的 NRP 骨架中已经提到芳香族生色团被 合成以后, 加载到载体蛋白上, 然后才能引发 NRP 骨架 的生物合成. 早期的放射性同位素标记喂养实验表明生 色团是由 $L$-色氨酸转化而来. 随着醌霉素生物合成基因 簇的确定，醌霉素生物合成假说也被提出，生色团的生 物合成的起始步骤普遍认为是 $L$-色氨酸加载到由 $\mathrm{A}$ 和 PCP 双结构域构成的 NRPS 蛋白上. 然而对该 NRPS 进 行在线生物信息学分析, 在线软件 (http://nrps.igs. umaryland.edu/nrps/cgi/nrps_parse.cgi)未能预测出此 A结构域识别的氨基酸, 而在线软件 (http://202.54.226. 229/ zeeshan/webpages/home.html)却预测此 A-结构域 识别的氨基酸为 $L$-苯丙氨酸. 于是上海交通大学由德林 课题组以 $S$. griseovariabilis subsp. bandungensis subsp. nov 中的棘霉素生物合成基因簇为对象，对该 NRPS 蛋 白 Qui18 的活性进行了体外研究, 确定了 A-PCP 双结构 域 NRPS 蛋白 Qui18 在类 MbtH 蛋白 Qui5 的必不可少 的辅助作用下，促成了棘霉素中的芳香族生色团喹喔啉 环生物合成起始步骤 $L$-色氨酸的加载. 并且 Qui5 和 Qui18 通过共表达形成二聚化的二聚体才能检测到其生 物活性 ${ }^{[10]}$.

\section{4 细胞色素 P450 羟化酶}

Novobiocin 和 nikkomycin 的生物合成与醌霉素的 生物合成经历了相似的反应，即起始步骤的氨基酸在类 MbtH 蛋白的辅助下, 加载到 NRPS 蛋白上. 并且此 3 种 抗生素的生物合成基因簇都具有细胞色素 P450 羟化酶 基因. Walsh 等 ${ }^{[22]}$ 在 2001 年报道了 novobiocin 中的香豆 
素结构单元的生物合成起始于 $L$-酪氨酸(19), 并用体外 实验证明了基因簇中细胞色素 P450 羟化酶 NovI 专一地 作用于 $L$-酪氨酰-S-NovH (21), 产物为 $(2 S, 3 R)$ - $\beta$-羟基- $L$ 酪氨酰-S-NovH (22) ${ }^{[22]}$ (图 3). 2002 年他们又报道了 nikkomycin 生物合成中的类似反应, 不同的是被羟化的 对象不再是 $L$-酪氨酸(19), 而是 $L$-组氨酸 $(\mathbf{2 0})$. 在细胞 色素 P450 羟化酶 NikQ 催化下, 生成 $(2 S, 3 R)-\beta$-羊基组氨酰-S-NikP (24) $^{[23]}$ (图 3). 这两组加载后的氨基酸 的 $\beta$-差化反应与醌霉素中的 $L$-色氨酸(1)被加载到 NRPS 蛋白发生羟化化类似, S. griseovariabilis subsp. bandungensis subsp. nov 中的棘霉素生物合成基因簇中 的细胞色素 P450 羟化酶 Qui15 被证实只能将加载到 NRPS 蛋白 Qui18 上的 $L$-色氨酸残基进行 $\beta$-差化, 生成 $(2 S, 3 S)-\beta$-羟基-色氨酰- $S$-Qui18, 而对游离的 $L$-色氨酸 不起作用 ${ }^{[10]}$.

\section{5 加载氨基酸从 A-PCP 双结构域的释放}

在棘霉素的生物合成基因簇中, 只有一个 II 型硫酯 酶基因, 它编码产物被推测负责羟基色氨酸从 NRPS 蛋 白上的释放, 然而在 thiocoraline 的生物合成基因簇中有 2 个 II 型硫酯酶基因, 为了确定与 HQA 生物合成途径 中氨基酸释放相关的 II 型硫酯酶, Mady 等 ${ }^{[24]}$ 在 thiocoraline 的产生菌中分别敲除了 A-PCP 双结构域基
因 $t i o K$ 和 2 个 II 型硫酯酶基因 $t i o P, t i o Q$, 发现 $t i o P$ 的 敲除对 thiocoraline 的产生丝毫没有影响, 而另外两个基 因的敲除均有明显影响. 接下来, 在体外用化学方法将 一系列酯酰基和氨酰基连接到辅酶 $\mathrm{A}$ 上形成连接产物 酯酰或氨酰辅酶 $\mathrm{A}$, 然后用磷酸泛酰巯基乙胺转移酶 Sfp 在体外将这些连接产物上的酯酰或氨酰磷酸泛酰颈 基乙胺结构单元转移到 TioK 的保守丝氨酸上, 用这些 加载到 TioK 上的底物, 检测硫酯酶 TioQ 针对这一系列 不同底物的体外活性(图 4), 最终发现虽然活性上略有 差异, 但 TioQ 能催化所有待试化合物释放相应的脂肪 酸或氨基酸, 从而将 TioQ 确定为负责 HQA 生物合成中 水解释放氨基酸的硫酷酶. 然而, 因为没有将生物合成 假说中预测的中间物羟基色氨酸加载到 TioK 上用来做 底物与其它底物进行比较, 这些体外证据尚不足以证明 加载到 $T i o K$ 上的羟基色氨酸即为硫酯酶 $T i o Q$ 的最适底 物, 但根据 TioQ 显示出的宽泛的底物专一性, 可以推 测加载到 TioK 上的羟基色氨酸也能被催化.

\section{6 色氨酸 2,3-双加氧酶 TDO}

色氨酸 2,3-双加氧酶(TDO)普遍存在于微生物和动 植物中, 在 $L$-色氨酸分解代谢的主代谢中作为催化第一 步反应的酶, 催化 $L$-色氨酸(1)的氧化开环生成 $N$-甲

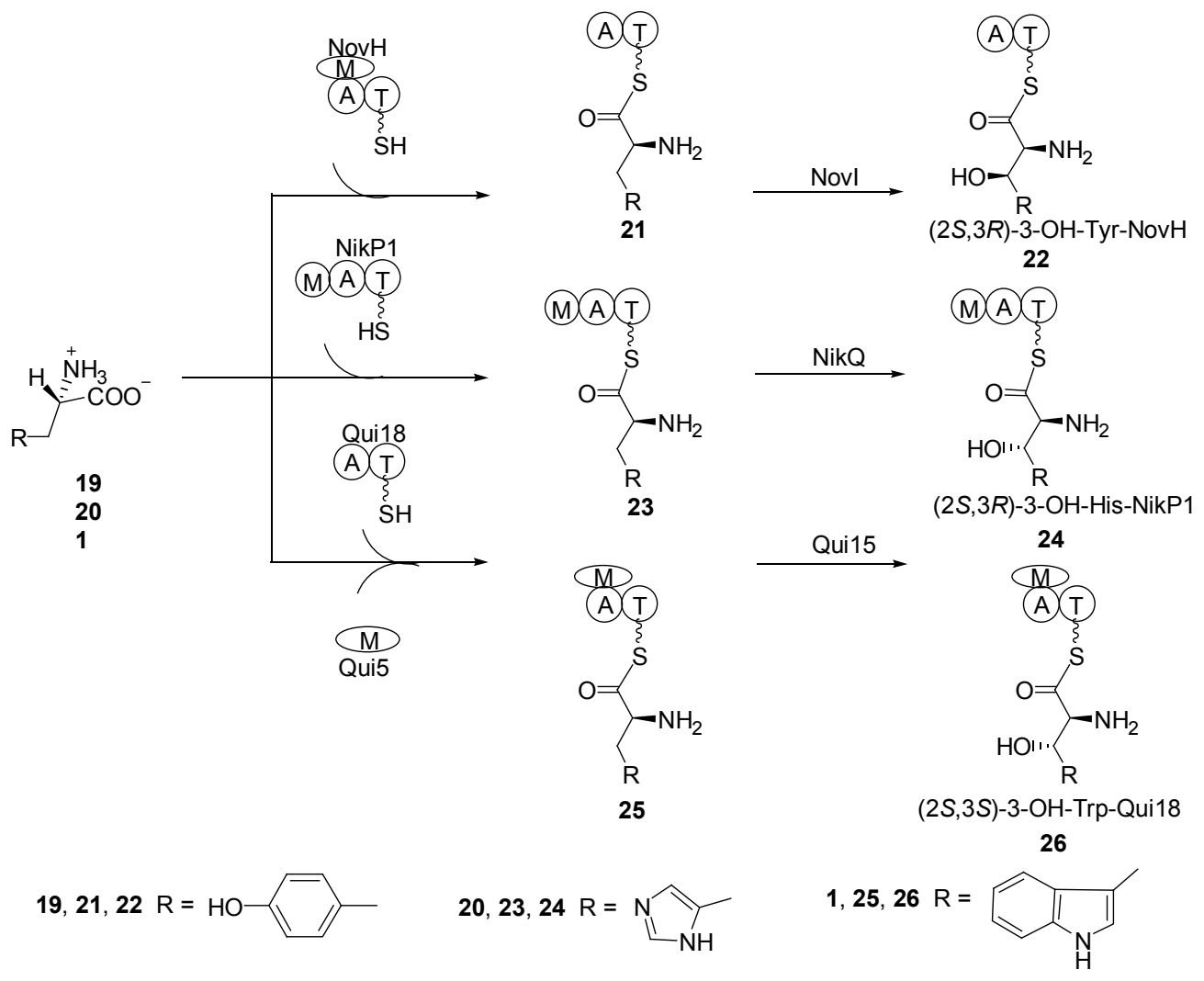

图 3 新生霉素、尼克霉素、棘霉素生物合成中的氨基酸加载与 $\beta$-羊圣化反应

Figure 3 Loading and $\beta$-hydroxylation of amino acid respectively in novobiocin, nikkomycin and echinomycin biosynthesis 


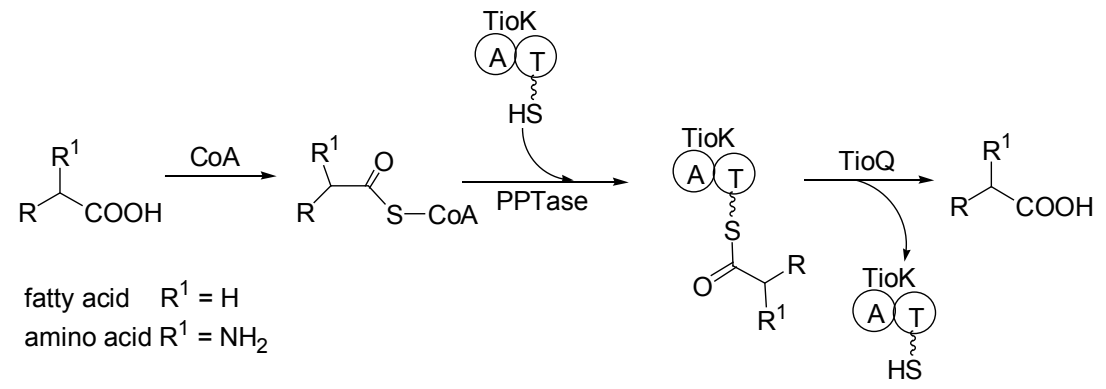

图 4 thiocoraline 生物合成中的硫酯酶基因 TioQ 的体外功能检测示意图

Figure 4 Ilustration of in vitro functional assay on the thioesterase TioQ for biosynthesis of thiocoraline

酰-犬尿氨酸(6)(图 2). 在醌霉素的生物合成基因簇内, 也发现了 TDO 基因, 根据放射性同位素喂养实验的结 果, Kenji Watanabe 推测该酶催化的反应与主代谢极为 类似，只是底物为 $(2 S, 3 S) \beta$-羟基色氨酸(4), 而非单纯的 $L$-色氨酸(1), 这一推测与前人对 TDO 的体外活性研究 得出的结论不符. 先前的研究认为 TDO 对 $L$-色氨酸具 有高度的专一性, 此外还能以较低的活性催化 6-氟色氨 酸, 而对其它所有试验过的色氨酸结构类似物均不能催 化 ${ }^{[25]}$. 上海交通大学由德林课题组 ${ }^{[10]}$ 按照 Watanabe 等 报道的化学方法合成了 4 作为底物,证明棘霉素生物合 成中的 TDO Qui17 确实能催化 $\mathbf{4}$ 的氧化开环, 生成 5 (图 2).

\section{4 醌霉素中的 NRP 骨架的生物合成、释放和 二硫键的重排}

\section{1 醌霉素的 NRP 骨架生物合成的概述}

一旦醌霉素的生色团被加载到载体蛋白上, 由 NRPS 蛋白促成的 NRP 肽链的延伸便开始进行, 这些 NRPS 都是由多个模块(module)构成的多酶体系, 其中 有些 module 除了最基本的 C, A, PCP 结构域之外, 还具 有能将氨基酸由 $L$ 型转化为 $D$ 型的 $\mathrm{E}$-结构域, 或具有能 将 NRP 骨架中的氨基酸残基的 $\alpha$-氮原子进行甲基化修 饰的 M-结构域, 此外都是利用包含在 NRPS 自身中的 II 型硫酯酶结构域将两条延伸至全长的完全相同的四肽 链以首尾相接的环二聚化方式释放, 形成大环内二酯 (图 5). 因此, 醌霉素不同成员间的大环内二酯 NRP 骨 架的差异是由 $\mathrm{A}$-结构域识别氨基酸的差异以及 $\mathrm{E}$ 结构 域和 $\mathrm{M}$ 结构域分布的不同造成的，从反应机制上来讲 并无本质差异. 释放形成的大环内二酯 NRP 需要经历 氧化酶催化的反应, 使来源于其中的两个半胱氨酸的颈 基氧化形成二硫键从而形成了三骨素 A、thiocoraline 和 SW-163C. 接下来, 在醌霉素某些成员的生物合成中, 二硫键被甲基转移酶催化形成硫缩醛结构, 使三骨素 A
经过一步反应转化为棘霉素. 因此, 醌需素成员的 NRP 骨架之间除了组成差异外, 还具有由特殊的甲基转移酶 催化造成的二硫键和硫缩醛的差异.

\section{2 醌霉素 NRP 骨架从 NRPS 上的释放}

在棘霉素的生物合成基因簇中, NRPS 蛋白 $\mathrm{Ecm} 7$ 的 末端有一个硫酯酶结构域将延伸完全的两条寡肽链进 行环二聚化, 从而使形成的大环内二酯从 $\mathrm{Ecm} 7$ 上释放 下来. 为了弄清这个 $\mathrm{TE}$-结构域的催化机制, Watanabe 等 ${ }^{[26]}$ 将这个 TE-结构域单独表达出来产生 EcmTE 蛋白, 用化学方法合成了棘霉素 NRP 骨架的四肽单元, 并得 到了在其 $\mathrm{N}$ 端和 $\mathrm{C}$ 端分别连接着喹喔啉-2-甲酰基和磷 酸泛酰疏基乙胺的结构类似物 SNAC 的化合物 27 , EcmTE 催化该底物产生了四肽单元二聚化的单酯 $\mathbf{2 8}$ 和 二酯 30. 通过非酶促的化学合成, 他们也得到了 28 , 并 且使其中的颈基氧化得到了具有二硫键的单酯 29, 该 产物在 EcmTE 催化下发生了两种不同反应, 一种是形 成二酯而环化, 另一种是 SNAC 从 $N$-甲基-线氨酸的羰 基水解下来, 产生两种产物为三骨素 $\mathrm{A}$ 和化合物 31, 它 们的产量比约为 $1: 2$. 此研究说明在单酯形成后, 第二 个酯键的形成与二硫键的形成在时间上没有严格的先 后顺序，此外，该 TE 催化的反应相比环化更容易向单 纯的水解方向进行, 副产物的产量几乎是三骨素 $\mathrm{A}$ 的 2 倍，从而显著影响了三骨素 $\mathrm{A}$ 的生物合成(图 6).

这些体外研究表明了硫醌酶催化活性的多向性，而 为了提高醌霉素的生物合成效率, 应该使该 $\mathrm{TE}$ 催化的 反应尽可能向生成二酯的方向进行. Watanabe 等 ${ }^{[26]}$ 巧妙 地利用三骨素对 DNA 结合的序列偏好性在体外达到了 这个目的，他们合成了具有其偏好序列 5'-ATAT-3'的多 核苷酸，同时也合成了半胱氨酸和顺氨酸残基的 $\alpha$-氮上 未被甲基化的四肽单元结构类似物，并将它偶联于 SNAC 上, 再将其二聚化并氧化形成具有二硫键的单酯 32. 以 32 为底物, 他们对比加入与不加入插入热点多核 苷酸的情况对 EcmTE 进行了体外酶学研究. 结果表明 


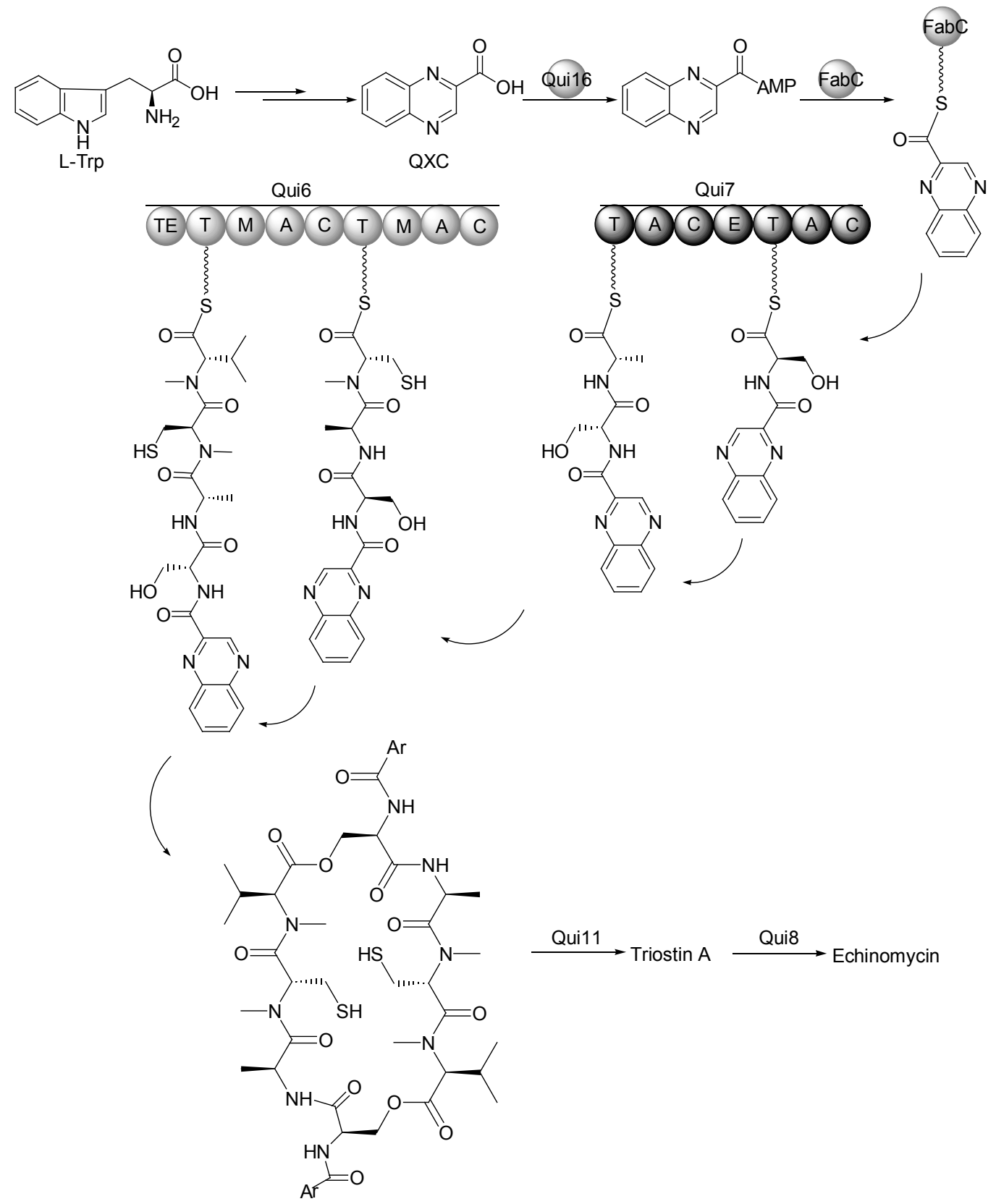

图 5 灰色变异链霉菌中醌霉素的非核糖体肽骨架的生物合成途径假说

Figure 5 Proposed NRP backbone biosynthetic pathway of quinomycin in S. griseovariabilis subsp. bandungensis subsp. Nov

加入该多核苷酸后，二酯产物 TANDEM34 与 SNAC 水 解产物 33 的产量比由未加入时的 $1: 2$ 变成了 $18: 1$. 也就反映了具有三骨素 A 插入热点多核苷酸对硫酯酶 环化反应的诱导作用. 他们推测该诱导作用可能是因为 该多核苷酸与底物形成的复合体 35 以某种构象抑制 SNAC 水解反应而不抑制环酯反应(图 7).

\section{3 二硫键向硫缩醛的转化}

Watanabe 等 ${ }^{[27]}$ 在棘霉素生物合成基因族中发现了 甲基转移酶 Ecm 18 并确定其功能后, 又在 SW-163 生物 合成基因簇中发现了两个与甲基化相关的蛋白 Swb8 和
$\mathrm{Swb} 9, \mathrm{Swb} 8$ 与 Ecm18 具有较高同源性, 而 Swb9 是一个 自由基 SAM 蛋白. SW-163 从 $\mathrm{C}$ 到 $\mathrm{G}$ 这 5 个组分, $\mathrm{C}$ 组 分含有二硫键, $\mathrm{D}$ 含有硫缩醛, 从 $\mathrm{E}$ 到 $\mathrm{G}$ 的每个组分含 有依次增加一个甲基的硫缩醛(图 1). 同样地, 他认为这 些组分的二硫键向硫缩醛的转化与基因簇中的甲基转 移酶有关.

结合同位素标记的[甲基-D3]- $L$-甲硫氨酸喂养实验, Watanabe 提出这样一个假说来解释上述转化. 首先是 由 Ecm 18 同源的 Swb8 催化一个甲基转移到二硫键的其 中一个硫上产生 36, 于是该硫带上一个正电荷，接 


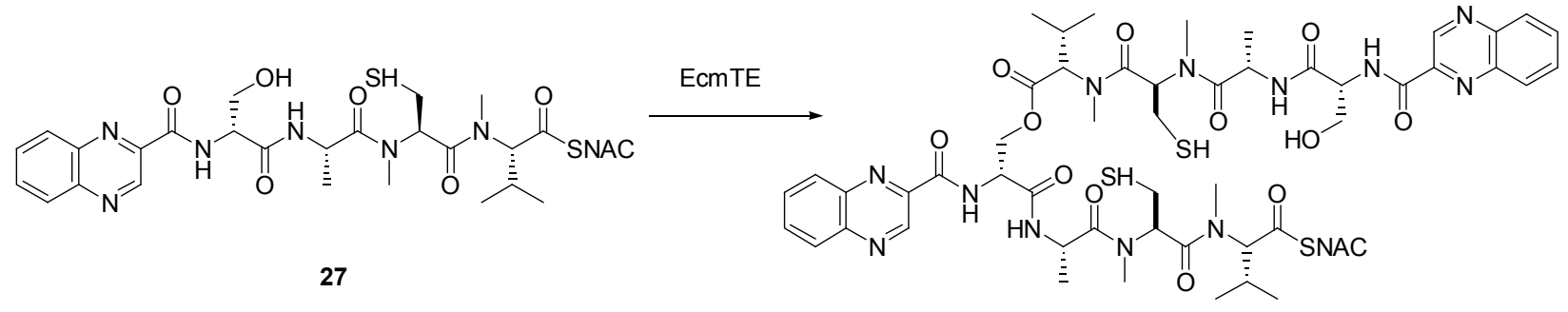

28<smiles>CC(=O)NCCSC=C=C(C)C(C)=O</smiles>

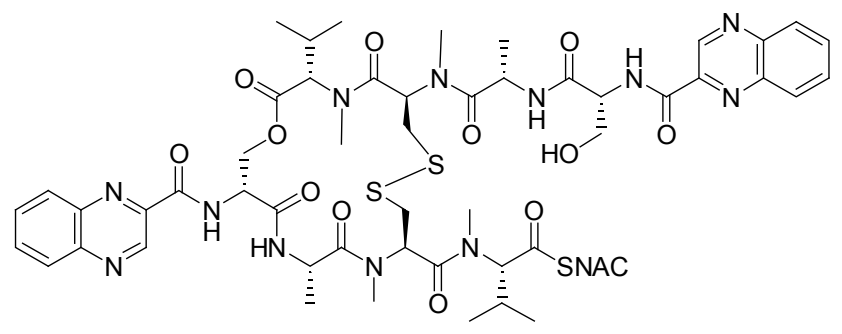

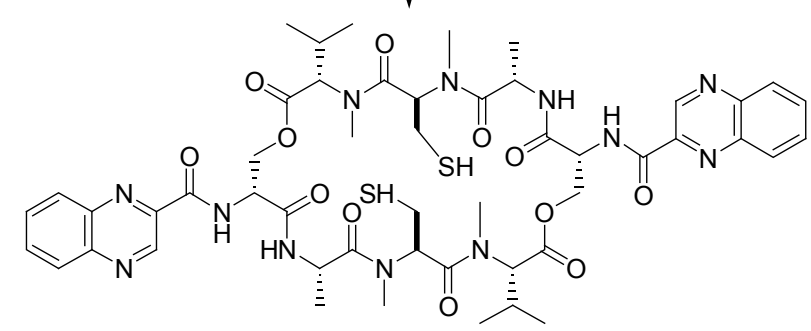

29

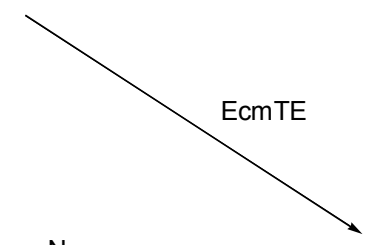

30

[O]

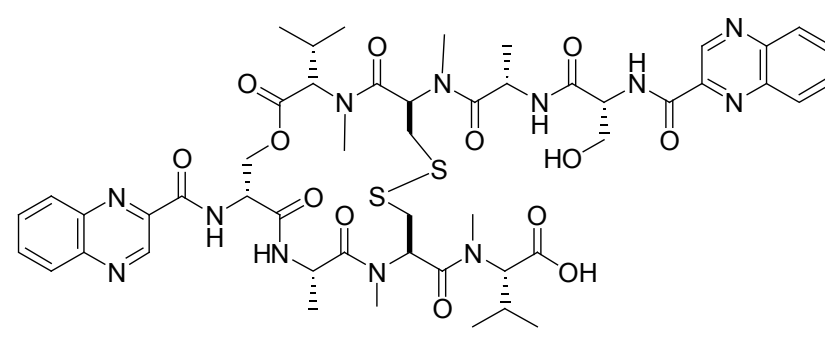

31

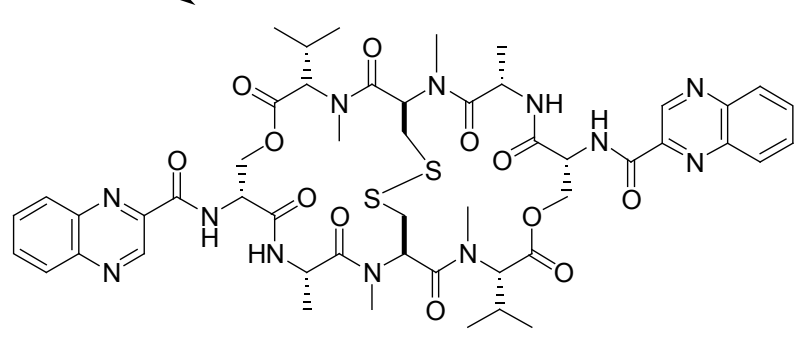

triostin A

图 6 棘霉素生物合成中 EcmTE 酶促反应的多样性

Figure 6 Diversity of EcmTE-mediated reaction in echinomycin biosynthesis

着由 Swb8 中的一个碱性氨基酸残基或是环境中的碱将 与该硫相邻的亚甲基上的一个氢原子夺走产生具有碳 负离子的 37, 然后发生非酶促的重排, 最终产生了硫缩 醛, 即为 SW-163D, 然后在 Swb9 的催化下, 由[4Fe-4S] ${ }^{+}$ 聚簇提供一个电子, SAM 分解产生了甲硫氨酸和一个 5'-脱氧腺苷自由基 38, 该自由基可以夺去 SW-163D 硫 缩醛甲基的一个氢原子, 使其变成硫缩醛自由基 39, 而 维生素 B12 钴胺素作为辅基又可以使其钴原子结合一 个甲基生成甲基钴胺素, 硫缩醛自由基可以将这个甲基 从维生素 B12 上夺走, 产生了一个带乙基的硫缩醛, 即 为 SW-163E. 同样, 每增加一个甲基都是按照相同的机 制进行，随后依次产生了 SW-163F 和 G(图 8) ${ }^{[27]}$.

\section{5 醌霉素的组合生物合成}

2006 年, Challis ${ }^{[28]}$ 在大肠杆菌中异源表达棘霉素的 生物合成基因并发酵得到棘霉素, 他的研究成为天然产 物异源表达的早期成功范例. 在此过程中, 他构建的异 源表达载体和发酵方法为天然产物的改造和异源表达 奠定了基础. 接下来, 醌霉素的多个成员的生物合成基 因簇又被克隆测序，并且通过序列分析，已经推测出其 中的功能基因，再结合同位素标记喂养实验和个别结构 基因的体外功能研究, 醌霉素生物合成途径终于被揭示 和证实. 2009 年, Kenji Watanabe 试图对醌需素家族进行 结构改造, 他将棘霉素 QXC 前体的生物合成基因连同 
<smiles>CC(=O)NCCSCCCCCCNC(=O)c1cnc2ccccc2n1</smiles>

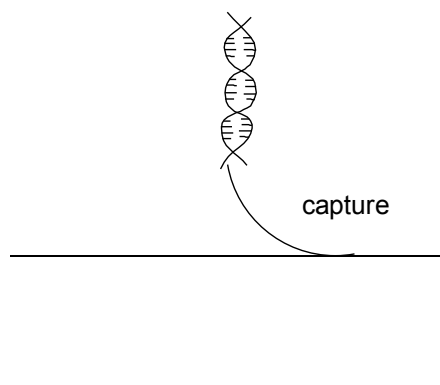

32
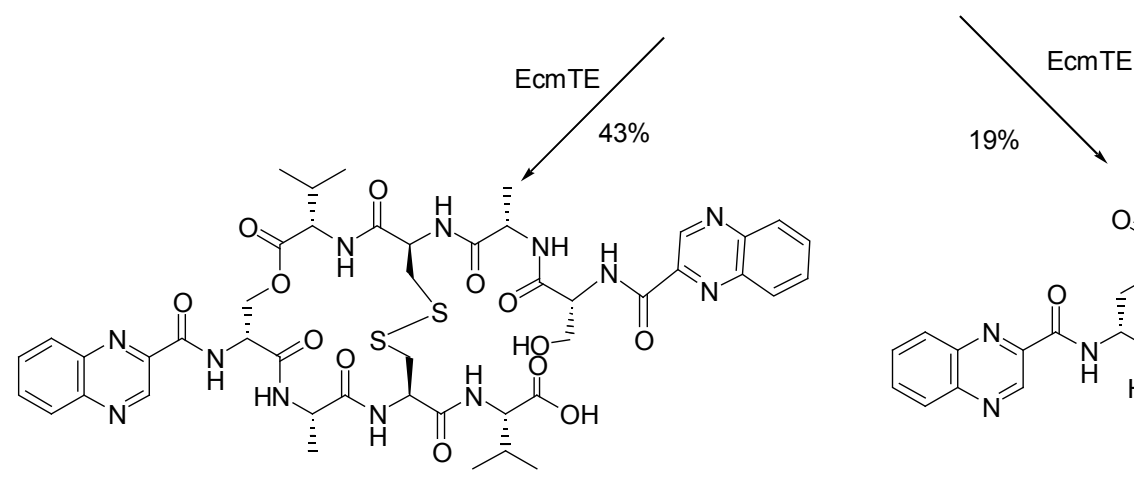

33
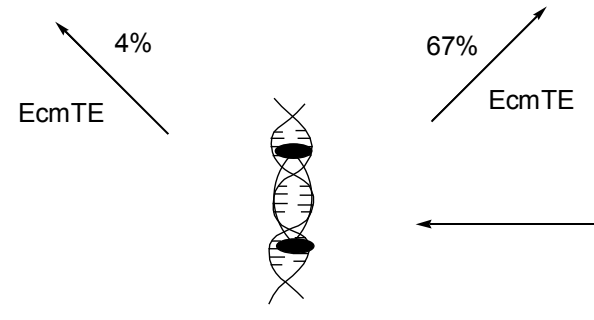

TANDEM

34

图 7 具有三骨素插入热点的多核苷酸对 EcmTE 环化反应的诱导作用

Figure 7 Inductive effect of triostin A intercalary hotspot bearing polynucleotide on the cyclization reaction catalyzed by EcmTE

对应于棘霉素 NRP 骨架四肽单元的丝氨酸和丙氨酸的 模块基因与 SW-163 生物合成基因簇中对应于半胱氨酸 和稀有氨基酸 NCA 的 NRPS 模块基因组合起来, 转化 到 E. coli BL21(图 9). 由于 NCA 的结构类似于冠烷酸 (coronamic acid), 他们预期 SW-163 的生物合成基因簇 中可能有冠烷酸生物合成基因的同源序列, 但最终并未 找到, 因此也就无法通过异源表达 NCA 的生物合成基 因在异源宿主大肠杆菌体内实现 $\mathrm{NCA}$ 的生物合成. 于 是, 他们在发酵培养基中直接添加 NCA, 以保证 NCA 能像形成 NRP 骨架的其它氨基酸一样有充足的来源而 被 NRPS 蛋白利用, 此外还在培养基中加入了芳香族前 体 QXC, 最终发酵得到了棘霉素和 SW-163 的结构嵌合 体 ecolimycin ${ }^{[27]}$. 其生色团为棘霉素的喹喔啉环, 而在 组成其 NRP 骨架四肽单元的氨基酸中, 前两者为棘霉 素中的丝氨酸和丙氨酸, 后两者为 SW-163 中的半胱氨 酸和 NCA.

此外, 他们根据之前报道过的自由基 SAM 脱氢酶 和赖氨酸 2,3-氨基变位酶的催化机制, 以及基因簇中发
现了自由基类型的 SAM 蛋白 Swb7 和依赖于吡哆醛-5'磷酸的氨基转移酶 Swb6 这个事实, 提出了 $\mathrm{NCA}$ 的生物 合成途径假说，该假说认为 NCA 的合成起始于 $L$-颉氨 酸(40)与 Swb6 辅基磷酸吡哆醛的缩合, 产生游离的磷 酸吡哆胺 (41), Swb7 通过铁硫族将 $L-M e t$ 转化为 5'-脱氧 腺苷自由基(38), 它能夺去 40 的 $\alpha$ 氢原子, 产生 $\alpha$ 碳自 由基 42, 该 $\alpha$ 碳进攻 42 的 $\gamma$ 碳产生具有环丙烷结构的 43, 同时释放出一个质子和一个电子, 这个电子又被 Swb7 的铁硫簇循环利用. 在 Swb6 催化下, 环丙烷结构 解离下来产生 NCA, 而磷酸吡哆醛又结合到 Swb6 上形 成磷酸吡哆胺(图 10) ${ }^{[27]}$.

\section{6 结束语}

近年来, 醌霉素家族成员的生物合成基因簇被确定 并且提出其生物合成途径假说. 目前, 其中的若干生化 反应都得到证实, 而且 Kenji Watanabe 用大肠杆菌异源 表达发酵产生醌霉素及其非天然的天然产物, 也为醌霉 


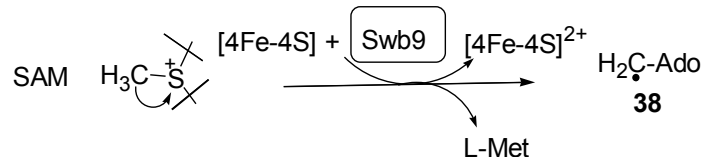

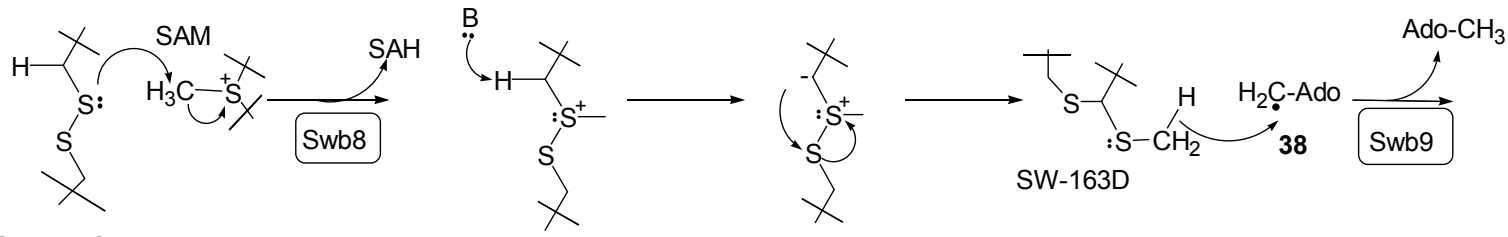

SW-163C

36

37
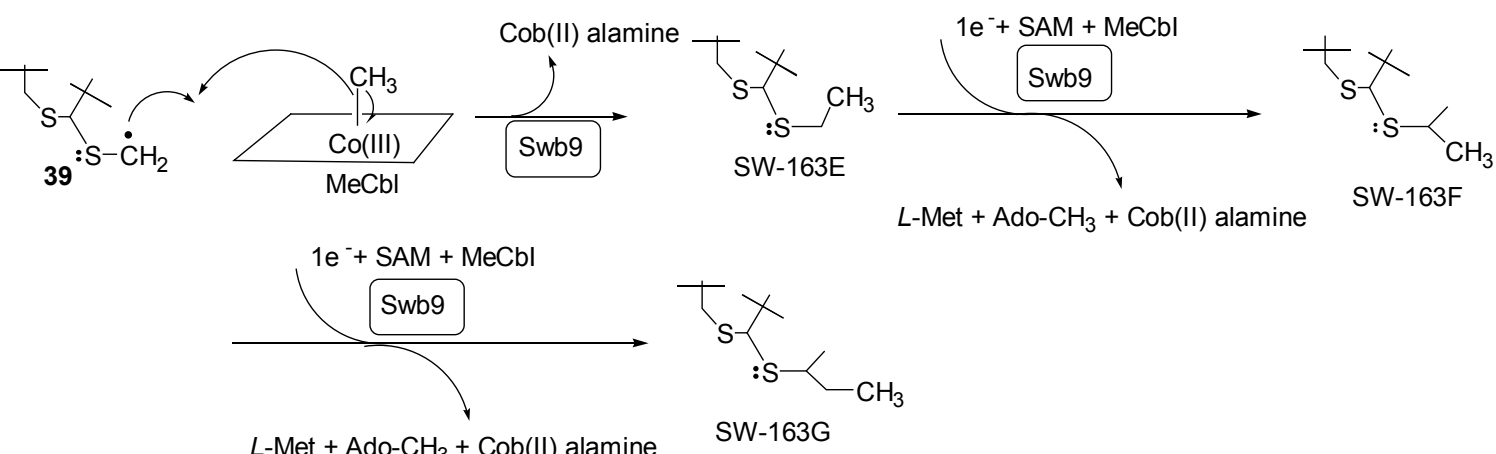

图 8 SW-163C 依次生成 SW-163D-G 的生物合成途径假说

Figure 8 Hypothesis about the sequential biosynthesis of SW-163D-G from SW-163C
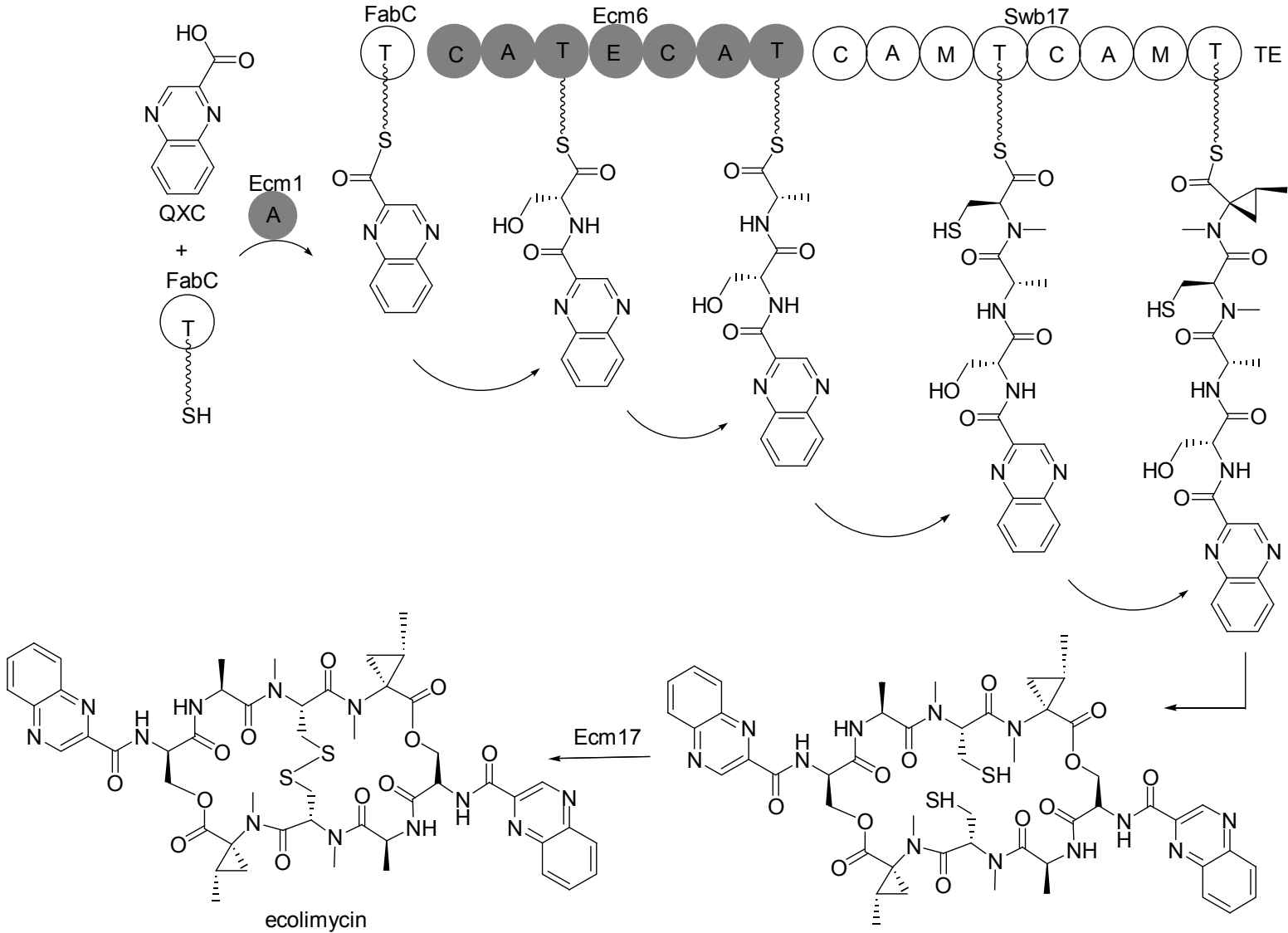

图 9 棘霉素与 SW-163 结构嵌合体化合物的组合生物合成策略

Figure 9 Tactic for combinatory biosynthesis of the structural chimera of echinomycin and SW-163 


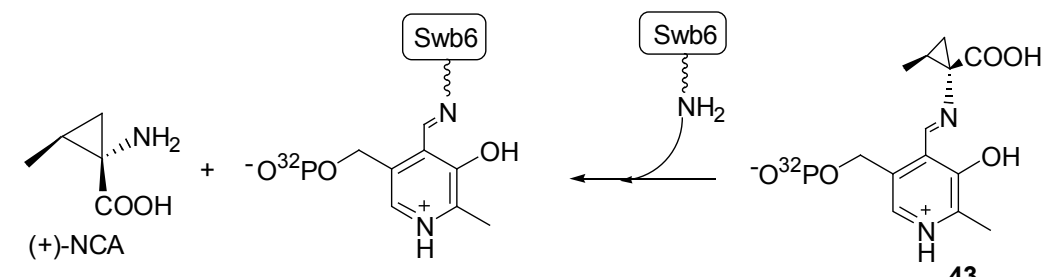

(+)-NCA

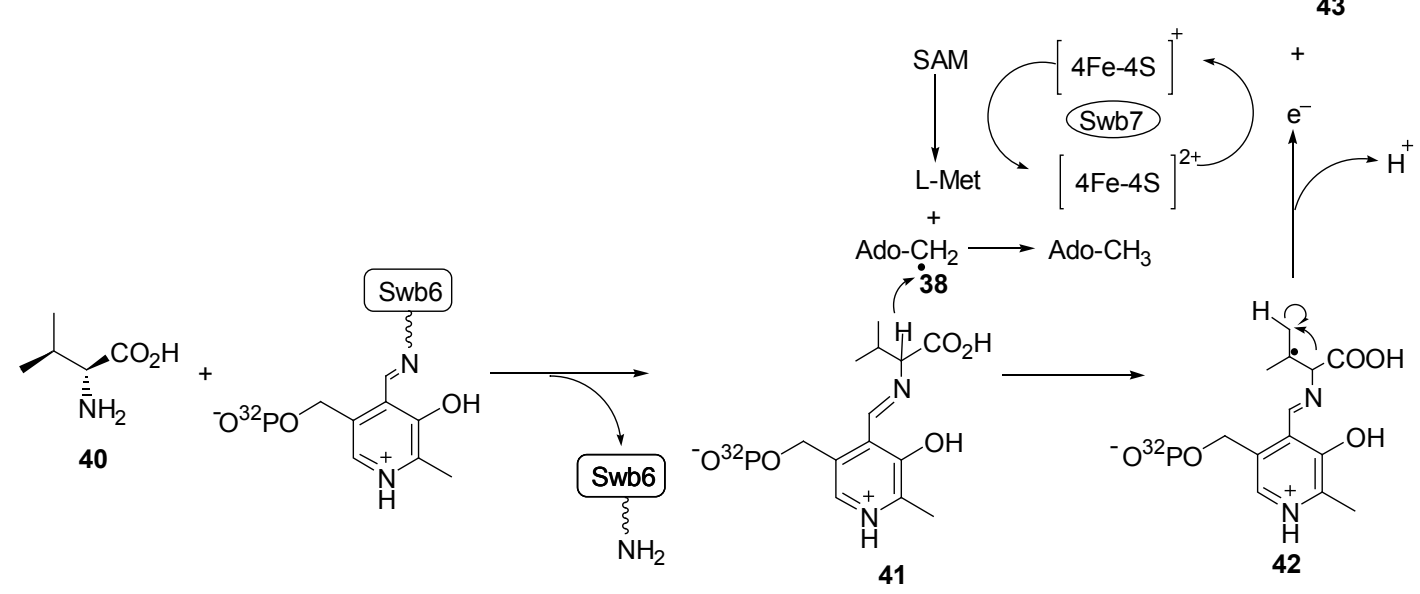

图 $10 \mathrm{NCA}$ 的生物合成途径假说

Figure 10 Hypothesis on NCA biosynthetic pathway

素生物合成的应用奠定了基础. 然而, 醌霉素的喹喔啉 环生色团的生物合成途径假说中, 羟基色氨酸氧化开环 之后的各步反应都有待证实. 特别是其中的一个依赖于 FAD 的氧化还原酶催化的反应, 除了发生氧化以外还 有一个重排, 这是一个极其罕见的反应; 此外, 假说认 为最后产生喹喔啉环之前, 发生了两步非酶促反应, 而 从化学的角度来说, 这两步反应在非酶促的条件下是很 难发生的. 因此, 对这些反应的研究很有可能会导致新 的生化反应机制的发现. 但目前最大的难度就在于, 这 些反应所需的底物很难用化学方法合成, 这将是今后重 点要解决的问题.

在醌霉素的生产应用方面, 由于醌霉素是由链霉菌 发酵产生, 密码子的偏好性可能会导致其生物合成基因 在大肠杆菌内翻译效率低下, 开发出有效的链霉菌宿 主, 或者将生物合成基因中的稀有密码子修改成大肠杆 菌中的惯用密码子, 而继续使用大肠杆菌作为宿主都可 能会大大提高其生产效率.

\section{References}

[1] Kleinkauf, H.; Döhren, H. V. Eur. J. Biochem. 1996, 236, 2.

[2] Hoffmeister, D.; Keller, N. P. Nat. Prod. Rep. 2007, 24, 2.

[3] Watanabe, K.; Oguri, H.; Oikawa, H. Curr. Opin. Chem. Biol. 2009, 13, 2 .

[4] Lee, J. S.; Waring, M. J. Biochem. J. 1978, 173, 1.

[5] Foster, B. J.; Clagett-Carr, K.; Shoemaker, D. D.; Suffness, M.; Plowman, J.; Trissel, L. A.; Grieshaber, C. K.; Leyland-Jones, B. Invest. New Drugs 1985, 3, 4.

[6] Glund, K.; Schlumbohm, W.; Bapat, M.; Keller, U. Biochemistry 1990, 29, 14.
[7] Schmoock, G.; Pfennig, F.; Jewiarz, J.; Schlumbohm, W.; Laubinger, W.; Schauwecker, F.; Keller, U. Biol. Chem. 2005, 280, 6.

[8] Watanabe, K.; Hotta, K.; Praseuth, A. P.; Koketsu, K.; Migita, A.; Boddy, C. N.; Wang, C. C.; Oguri, H.; Oikawa, H. Nat. Chem. Biol. 2006, 2,8 .

[9] Praseuth, A. P.; Wang, C. C.; Watanabe, K.; Hotta, K.; Oguri, H.; Oikawa, H. Biotechnol. Prog. 2008, 24, 6.

[10] Zhang, C.; Kong, L. X.; Liu, Q.; Lei, X.; Zhu, T.; Yin, J. PLoS One. 2013, $8,2$.

[11] Lombo, F.; Velasco, A.; Castro, A.; de la Calle, F.; Brana, A. F.; Sánchez-Puelles, J. M.; Méndez, C.; Salas, J. A. ChemBioChem 2006, 7, 2 .

[12] Koketsu, K.; Oguri, H.; Watanabe, K.; Oikawa, H. Org. Lett. 2006, $8,21$.

[13] Sheoran, A.; King, A.; Velasco, A.; Pero, J. M.; GarneauTsodikova, S. Mol. Biosyst. 2008, 4, 6 .

[14] Watanabe, K.; Hotta, K.; Nakaya, M.; Praseuth, A. P.; Wang, C. C.; Inada, D.; Takahashi, K.; Fukushi, E.; Oguri, H.; Oikawa, H. J. Am. Chem. Soc. 2009, 131, 26.

[15] Felnagle, E. A.; Barkei, J. J.; Park, H.; Podevels, A. M.; McMahon, M. D.; Drott, D. W.; Thomas, M. G. Biochemistry 2010, 49, 41.

[16] Zhang, W.; Heemstra, J. J.; Walsh, C. T.; Imker, H. J. Biochemistry 2010, 49, 46.

[17] Baltz, R. H. J. Ind. Microbiol. Biotechnol. 2011, 38, 11.

[18] Wolpert, M.; Gust, B.; Kammerer, B.; Heide, L. Microbiology 2007, 153, 5.

[19] Van, L. S.; Lin, S.; Dorrestein, P. C.; Kelleher, N. L.; Shen, B. J. Biol. Chem. 2006, 281, 40.

[20] Boll, B.; Taubitz, T.; Heide, L. J. Biol. Chem. 2011, 286, 42.

[21] Herbst, D. A.; Boll, B.; Zocher, G.; Stehle, T.; Heide, L. J. Biol. Chem. 2013, 288, 3.

[22] Chen, H.; Walsh, C. T. Chem. Biol. 2001, 8, 4.

[23] Chen, H.; Hubbard, B. K.; O'Connor, S. E.; Walsh, C. T. Chem. Biol. 2002, 9, 1.

[24] Mady, A. S.; Zolova, O. E.; Millan, M. A.; Villamizar, G.; de la 
Calle, F.; Lombó, F.; Garneau-Tsodikova, S. Mol. Biosyst. 2011, 7, 6.

[25] Forouhar, F.; Anderson, J. L.; Mowat, C. G.; Vorobiev, S. M.; Hussain, A.; Abashidze, M.; Bruckmann, C.; Thackray, S. J.; Seetharaman, J.; Tucker, T.; Xiao, R.; Ma, L. C.; Zhao, L.; Acton, T. B.; Montelione, G. T.; Chapman, S. K.; Tong, L. Proc. Natl. Acad. Sci. U. S. A. 2007, 104, 2.
[26] Koketsu, K.; Oguri, H.; Watanabe, K.; Oikawa, H. Chem. Biol. 2008, 15,8 .

[27] Watanabe, K.; Hotta, K.; Nakaya, M.; Praseuth, A. P.; Wang, C. C.; Inada, D.; Takahashi, K.; Fukushi, E.; Oguri, H.; Oikawa, H. J. Am. Chem. Soc. 2009, 131, 26.

[28] Challis, G. L. Nat. Chem. Biol. 2006, $2,8$.

(Zhao, X.) 